\title{
Pelaksanaan Supervisi Akademik oleh Kepala Sekolah Menengah Pertama Negeri di Klaten Jawa Tengah
}

\author{
Pandit Isbianti $^{*}$, Dwi Esti Andriani ${ }^{1}$ \\ ${ }^{1}$ Universitas Negeri Yogyakarta, Yogyakarta, DIY, Indonesia
}

Corresponding author: Pandit Isbianti (e-mail: panditisbianti@uny.ac.id)

\begin{abstract}
Abstrak: Supervisi akademik merupakan salah satu tugas dan tanggung jawab utama kepala sekolah. Penelitian ini bertujuan untuk mendeskripsikan pelaksanaan supervisi kepala sekolah menengah pertama negeri (SMPN) menurut persepsi guru. Penelitian dilaksanakan di Kecamatan Jatinom, Klaten, Jawa Tengah dengan menyebarkan angket ke 109 orang guru di tiga sekolah yang dipilih. Angket penelitian yang digunakan telah divalidasi menggunakan teknik expert judgement. Data dari angket diolah secara kuantitatif dengan teknik persentase. Hasil penelitian menunjukkan bahwa kepala SMPN yang diteliti telah melaksanakan tugastugas supervisi akademik. Dari keseluruhan tugas, tugas memotivasi guru untuk memanfaatkan teknologi informasi dalam pembelajaran di setiap mata pelajaran merupakan tugas yang paling tinggi keterlaksanaannya. Sebaliknya, tugas yang paling rendah keterlaksanaannya adalah membimbing guru menyusun silabus tiap mata pelajaran sesuai dengan kurikulum yang berlaku. Dengan demikian, pelaksanaan supervisi akademik kepala sekolah di beberapa area masih perlu ditingkatkan.
\end{abstract}

Kata Kunci: supervisi akademik, kekepalasekolahan

\section{Academic Supervision Practices of Junior High School Principals in Klaten, Central Java}

\begin{abstract}
Academic supervision is one of the main duties and responsibilities of a school principal. This study aims to describe the academic supervision practices of the principals in public junior high schools (SMPN) based on teachers' perception. This study was conducted in Jatinom, Klaten District, Central Java Province, by distributing a questionnaire to 109 teachers in three selected SMPNs. The questionnaire had been validated using the expert judgment technique. The data collected from the questionnaire were analysed quantitatively. The findings show that the public junior high school principals supervised the teachers regarding their teaching-related responsibilities. The prominent supervision practice exercised by the principals was motivating teachers to take advantage of information technology in teaching. The weakest one performed by the principals was related to helping teachers in developing syllabus as required by the current national curriculum. Thus, school principal academic supervision practices in some areas still need improvement.
\end{abstract}

Keyword: academic supervision, principalship 


\section{PENDAHULUAN}

Kepala sekolah merupakan pemimpin sekaligus penanggung jawab penyelenggaraan pembelajaran yang berkualitas di sekolah. Oleh karena itu, kepala sekolah perlu mengembangkan profesionalisme dan kinerja guru di sekolahnya. Salah satu upaya yang dapat dilakukan yaitu melaksanakan supervisi akademik. Hasil penelitian di Nigeria menunjukkan bahwa supervisi pengajaran menempati posisi penting dalam sistem pendidikan dan perlu mendapatkan perhatian yang serius sebagai strategi untuk meningkatkan pertumbuhan profesional guru, kurikulum dan teknik mengajar di kelas (Okendu, 2012). Di Indonesia, kompetensi kepala sekolah melaksanakan supervisi telah diamanatkan Permendiknas RINo 13 tahun 2007 tentang Standar Kompetensi Kepala Sekolah. Peraturan ini menetapkan bahwa lima standar kompetensi kepala sekolah yaitu kompetensi kepribadian, sosial, manajerial, kewirausahaan, dan supervisi.

Supervisi akademik merupakan kegiatan pembimbingan profesional kepada guru agar mereka mampu melaksanakan tugas mengajarnya dengan baik (Prasojo \& Sudiyono, 2011; Sergiovanni, 1987). Indikator utamanya yaitu guru mampu mengembangkan pembelajaran siswa yang aktif, kreatif, inovatif, efektif, efisien, dan menyenangkan. Objek supervisi akademik meliputi materi pembelajaran, silabus, dan Rencana Pelaksanaan Pembelajaran (RPP), metode pembelajaran, penggunaan media dan teknologi informasi dalam pembelajaran, penilaian, hasil pembelajaran, serta penelitian tindakan kelas. Tujuannya yaitu pengembangan profesionalisme guru, pemantauan kualitas pembelajaran, dan peningkatan motivasi kerja guru (Sergiovanni, 1987).

Supervisi akademik hendaknya menerapkan pendekatan yang tepat. Pendekatan supervisi berdasarkan teori pengembangan Erickson dan Piaget dibagi menjadi empat. (1) Gaya control directive, gaya ini digunakan apabila level pengembangan diri guru rendah. Guru tidak memiliki kemauan, pengetahuan, dan bersikap pasif, serta tidak mau terlibat dalam pengambilan keputusan. Dibandingkan guru, supervisor lebih berkomitmen memecahkan masalah. (2) Gaya informational directive, gaya ini digunakan bila level pengembangan guru agak rendah. Guru tidak memiliki pengetahuan dan pengalaman serta tidak tahu apa yang harus dilakukan untuk pengembangan dirinya. Supervisor peduli terhadap permasalahan guru dan berperan sebagai sumber utama informasi. (3) Gaya behaviors collaborative, gaya ini digunakan bila level pengembangan guru moderat, guru dan supervisor memiliki tingkat keahlian yang sama, dan bersama-sama berkomitmen untuk memecahkan masalah. (4) Gaya behaviors non directive, digunakan bila level pengembangan guru tinggi dimana guru memiliki keahlian, inisiatif dan komitmen untuk memecahkan masalah (Glickman, Gordon, \& Ross, 
2010). Supervisor hendaknya memilih pendekatan yang paling sesuai dengan tingkat perkembangan guru. Rahabav (2016) mengatakan bahwa pendekatan supervisi yang tepat dapat meningkatkan motivasi kerja guru dalam mengajar, kesiapan guru mengajar dan kualitas proses pembelajaran.

Supervisi akademik yang efektif membutuhkan perencanaan (Direktorat Jenderal Guru dan Tenaga Kependidikan, 2019a) yaitu proses menetapkan tujuan supervisi dan strategi pencapaiannya yang dipertimbangkan efektif untuk sasaran yang ditetapkan. Perencanaan supervisi ini perlu dilakukan secara obyektif, bertanggungjawab, berkelanjutan, didasarkan mengacu pada Standar Nasional Pendidikan, dan didasarkan padakebutuhan sekolah/madrasah (Prasojo \& Sudiyono, 2002). Proses perencanaan supervisi akademik juga perlu menyiapkan perangkat supervisi seperti daftar lengkap sekolah dan guru yang disupervisi, kegiatan pembelajaran tahunan, bulanan, dan mingguan, jadwal kunjungan kelas, dan instrumen supervisi (Thaib, dkk, 2005:46-49).

Supervisi akademik yang telah direncanakan hendaknya dilaksanakan dengan baik. Supervisor perlu membuat persiapan, penjadwalan dan sosialisasi terlebih dahulu kepada guru yang akan disupervisi. Selain itu, supervisor juga perlu memilih teknik supervisi yang tepat beserta instrumennya (Burhanuddin, 2005). Makawimbang $(2011$, 117) menyebutkan berbagai teknik supervisi yang mungkin digunakan:

a. Kunjungan dan observasi kelas

Kunjungan dan observasi kelas ditujukan untuk mencari informasi tentang bagaimana proses pembelajaran berlangsung di dalam kelas. Sasaran observasinya antara lain penggunaan metode, alat dan media pengajaran, penugasan pada siswa, penyiapan silabus dan pengkondisian kelas. Hasil observasi menjadi bahan refleksi dan tindak lanjut supervisi.

b. Pembicaraan individual

Pembicaraan individual merupakan teknik supervisi dimana supervisor dan yang disupervisi melakukan pertemuan dan pembicaraan secara personal. Di dalam pertemuan personal ini, supervisor perlu mengembangkan segi-segi positif guru, mendorong guru mengatasi kesulitan-kesulitannya, dan memberikan pengarahan tentang apa yang harus dilakukan oleh guru untuk meningkatkan kualitas pengajarannya.

c. Diskusi kelompok

Diskusi kelompok merupakan forum pertemuan dimana orang-orang di dalamnya saling tukar pendapat. Tujuannya bagi guru yaitu mendapatkan strategi untuk 
memperbaiki kualitas pengajaran. Forum pertemuan ini dapat berupa, workshop, diklat, bimtek, rapat guru dan lainnya.

d. Demonstrasi mengajar

Demonstrasi mengajar merupakan suatu kegiatan dimana guru profesional mendemonstrasikan cara mengajar yang efektif kepada guru-guru lain. Harapannya, guru-guru dapat belajar dari apa yang didemonstrasikan dalam rangka peningkatan kemampuan mengajar mereka.

Pelaksanaan kegiatan supervisi diakhiri dengan tindak lanjut dan pelaporan hasil kepada guru (Burhanuddin, 2005). Lantip dan Sudiyono (2011: 123) menyarankan beberapa tindakan sebagai tindak lanjut suatu laporan supervisi yaitu:

a. mereview rangkuman hasil penilaian,

b. jika tujuan supervisi akademik dan standar-standar pembelajaran belum tercapai, supervisor hendaknya melakukan penilaian ulang terhadap pengetahuan, keterampilan, dan sikap guru yang menjadi tujuan pembinaan atau merancang kembali program supervisi akademik guru untuk masa berikutnya,

c. membuat rencana aksi supervisi akademik berikutnya,

d. mengimplementasikan rencana aksi tersebut pada masa berikutnya.

Kajian di atas menunjukkan bahwa supervisi akademik perlu direncanakan, dilaksanakan, dan dievaluasi secara sistematis oleh kepala sekolah. Penelitian ini bertujuan untuk memperoleh deskripsi pelaksanaan supervisi akademik kepala sekolah menengah pertama negeri (SMPN) menurut guru. Hasil penelitian ini memiliki manfaat teoritis di Indonesia yaitu memperkaya kajian tentang supervisi akademik kepala sekolah di negeri ini.

\section{METODE PENELITIAN}

Penelitian ini merupakan penelitian deskriptif kuantitatif. Penelitian deskriptif bertujuan menggambarkan fenomena yang sedang terjadi secara sistematis, faktual, dan akurat mengenai fakta-fakta dan sifat-sifat fenomena yang diselidiki (Rukajat, 2018). Penelitian ini juga merupakan penelitian kuantitatif karena gejala-gejala yang diteliti akan dianalisis, diukur, dan ditampilkan dengan angka-angka (Arikunto, 2013).

Penelitian mengambil lokasi di tiga SMPN di Kecamatan Jatinom, Kabupaten Klaten, Jawa Tengah. Responden penelitian meliputi semua guru di tiga sekolah tersebut yang berjumlah 109 orang. Mereka diminta mengisi angket yang dikembangkan berdasarkan kajian teori tentang pelaksanaan supervisi akademik. Pengembangan angket menghasilkan tujuh indikator yaitu (1) pemahaman kepala sekolah tentang konsep, prinsip, teori/teknologi, 
karakteristik, dan kecenderungan perkembangan proses pembelajaran/bimbingan tiap mata pelajaran di SMP, (2) pembimbingan guru dalam menyusun silabus tiap mata pelajaran sesuai dengan kurikulum yang berlaku, (3) pembimbingan guru dalam memilih dan menggunakan strategi/metode/teknik pembelajaran dengan melihat RPP, (4) perencanaan kolaboratif kegiatan supervisi bersama guru, (5) monitoring pelaksanaan pe mbelajaran yang dilakukan guru, (6) evaluasi kegiatan pembelajaran yang dilakukan guru, dan (7) pemotivasian guru untuk memanfaatkan teknologi informasi di setiap mata pelajaran.

Angket penelitian bersifat tertutup dengan dua pilihan jawaban yaitu "ya' dan "tidak". Responden memilih jawaban dengan membubuhkan tanda silang $(\mathrm{x})$ atau checklist $(\sqrt{ })$. Angket dengan tipe jawaban tegas seperti “ya" dan "tidak" ini perlu menerapkan skala Guttman. Skala Guttman merupakan skala dua interval yang digunakan untuk mendapatkan jawaban yang tegas dari responden seperti “ya, tidak”. Skala pengukuran ini dapat menghasilkan pertanyaan dalam bentuk pilihan ganda maupun checklist dengan skor jawaban tertinggi (ya) satu dan terendah (tidak) nol (Sugiyono 2014:139). Untuk menguji validitasnya, penelitian ini menggunakan expert judgement yang melibatkan pakar di bidang supervisi pendidikan.

Data penelitian ini dianalisis menggunakan teknik analisis data deskriptif kuantitatif dengan teknik pengukuran persentase (Winarsunu, 2002). Teknik ini memungkinkan deskripsi data yang menunjukkan keterlaksanaan tugas-tugas supervisi akademik kepala sekolah.

\section{HASIL}

Hasil penelitian menunjukkan bahwa menurut guru, sebagian besar kepala sekolah di tiga SMPN telah melaksanakan tugas-tugas supervisi akademik dengan pencapaian skor $86 \%$. Dengan kata lain, 95 guru memperoleh bimbingan atau supervisi akademik dari kepala sekolahnya. Hasil penelitian secara lebih detail disajikan dalam tabel 1.

Tabel1.Pembinaan kompetensi profesional guru melalui supervisi pengajaran

\begin{tabular}{llcccc}
\hline No & \multicolumn{1}{c}{ Indikator } & Ya & $\begin{array}{c}\text { Persentase } \\
(\boldsymbol{\%})\end{array}$ & Tidak & $\begin{array}{c}\text { Persentase } \\
(\%)\end{array}$ \\
\hline 1 & $\begin{array}{l}\text { Memahami konsep, prinsip, teori/teknologi, } \\
\text { karakteristik, dan kecenderungan perkembangan } \\
\text { proses pembelajaran/bimbingan tiap mata pelajaran }\end{array}$ & 96 & 88,07 & 13 & 11,93 \\
2 & $\begin{array}{l}\text { Membimbing guru dalammenyusun sila bus tiap mata } \\
\text { pelajaran sesuaidengan kurikulum yang berlaku }\end{array}$ & 78 & 71,56 & 31 & 28,44 \\
3 & $\begin{array}{l}\text { Membimbing guru dalam memilih dan menggunakan } \\
\text { strategi/metode/teknik pembelajaran dengan melihat }\end{array}$ & 85 & 77,52 & 24 & 22,48 \\
$\quad \begin{array}{l}\text { RPP } \\
\text { Melakukan perencanaan kegia tan supervisi bersama } \\
\text { guru } \\
\text { Memonitor pelaksanaan pembelajaran yang dilakukan } \\
\text { oleh guru }\end{array}$ & 97 & 88,99 & 12 & 11,01 \\
& 89,91 & 11 & 10,09
\end{tabular}




\begin{tabular}{llcccc}
\hline No & \multicolumn{1}{c}{ Indikator } & Ya & $\begin{array}{c}\text { Persentase } \\
(\mathbf{\%})\end{array}$ & Tidak & $\begin{array}{c}\text { Persentase } \\
(\boldsymbol{\%})\end{array}$ \\
\hline 6 & $\begin{array}{l}\text { Melakukan evaluasi kegiatan pembelajaran yang } \\
\text { dilakukan guru }\end{array}$ & 101 & 92,66 & 8 & 7,34 \\
7 & $\begin{array}{l}\text { Memotivasi guru untuk memanfaatkan teknologi } \\
\text { informasi dalam pembelajaran disetiap mata pelajaran }\end{array}$ & 107 & 98,17 & 2 & 1,83 \\
\hline$\quad$ Rata-rata(\%) & 94,6 & $86,7 \%$ & 14,4 & $13,3 \%$ \\
\hline
\end{tabular}

Tabel 1 menunjukkan ada perbedaan skor keterlaksanaan tugas-tugas supervisi akademik. Skor tertinggi yaitu 98,17\% (107 guru) berada di indikator ketujuh yakni "memotivasi guru untuk memanfaatkan teknologi informasi dalam pembelajaran disetiap mata pelajaran". Ini berarti kepala sekolah telah memotivasi guru-gurunya ketika melaksanakan supervisi. Skor terendah 71,56\% (78 responden) berada di indikator kedua yakni membimbing guru dalam menyusun silabus tiap mata pelajaran sesuai dengan kurikulum yang berlaku. Dengan kata lain, sekitar 31 guru menyatakan kepala sekolah tidak membimbing mereka dalam menyusun silabus tiap mata pelajaran sesuai dengan kurikulum yang berlaku.

\section{PEMBAHASAN}

Hasil penelitian menunjukan adanya variasi keterlaksanaan tugas-tugas supervisi akademik oleh kepala sekolah di tiga sekolah yang diteliti. Kondisi ini perlu mendapatkan perhatian mempertimbangkan pentingnya supervisi akademik untuk menguatkan atau mengembangkan kompetensi guru. Berikut pembahasan hasil penelitian pelaksanaan supervisi ak ademik kepala sekolah yang disajikan per indikator secara berurutan.

\subsection{Memahami konsep, prinsip, teori/teknologi, karakteristik, dan kecenderungan perkembangan proses pembelajaran/bimbingan tiap mata pelajaran}

Memahami konsep, prinsip, teori/teknologi, karakteristik, dan kecenderungan perkembangan proses pembelajaran/bimbingan tiap mata pelajaran merupakan salah satu indikator pelaksanaan supervisi akademik kepala sekolah. Pemahaman tersebut penting untuk dimiliki oleh kepala sekolah mengingat tugasnya sebagai perencana sekaligus pelaksana utama supervisi akademik. Keberhasilan proses supervisi akademik ini akan terwujud apabila didukung oleh keterampilan konseptual kepala sekolah (Novianti, 2015).

Hasil penelitian menurut sebagian besar responden yaitu 88,07\% atau 96 guru menunjukkan bahwa kepala sekolah memahami konsep, prinsip, teori, karakteristik dan perkembangan proses pembelajaran. Pemahaman kepala sekolah tentang perkembangan konsep, teori, serta proses pembelajaran ini akan memudahkan mereka dalam membimbing guru. Harapannya, supervisi akademik yang sasaran utamanya adalah pengembangan 
keterampilan mengajar guru dapat menghasilkan perubahan pada diri guru yang berdampak besar pada kualitas pembelajaran.

\subsection{Membimbing guru dalam menyusun silabus tiap mata pelajaran sesuai dengan kurikulum yang berlaku}

Proses pembelajaran merupakan kegiatan inti sekolah yang diarahkan pada kemajuan sekolah. Keberhasilan proses pembelajaran membutuhkan persiapan mengajar yang matang dari guruguru. Dengan kata lain, guru perlu menyusun silabus, yaitu rancangan materi pembelajaran yang disajikan secara berurutan sebagai bagian dari dokumen kurikulum sebelum melaksanakan pengajaran (Chanie, 2013). Silabus merupakan komponen penting dalam pembelajaran sehingga perlu serius dipersiapkan oleh guru.

Pembimbingan penyusunan silabus oleh kepala SMPN menurut guru telah dilakukan kepala sekolah walaupun tidak selalu. Hal ini diindikasikan dari jawaban "ya" yang terbatas pada 78 guru atau 71,56\%. Dengan kata lain, kepala sekolah kadang tidak melakukan pembimbingan penyusunan silabus kepada guru-gurunya. Kondisi ini perlu mendapat perhatian mempertimbangkan peran penting kepala sekolah sebagai pengendali mutu pembelajaran. Terlebih, guru seringkali menemui masalah penyusunan silabus dalam kerangka kurikulum 2013 yang saat ini berjalan dan mengharapkan kepala sekolah sebagai tempat untuk bertanya dan mencari pencerahan. Terkait hal ini, Kuncoro, Suntoro \& Kandar (2015) mengatakan bahwa jika perubahan terhadap kurikulum relatif besar, kepala sekolah perlu menguasai kurikulum.

\subsection{Membimbing guru dalam memilih dan menggunakan metode pembelajaran dengan melihat RPP}

RPP merupakan rencana yang menggambarkan prosedur dan pengorganisasian pembelajaran untuk mencapai satu kompetensi dasar yang telah ditetapkan dalam standar isi dan dijabarkan dalam silabus (Susetya, 2017). Ruang lingkup terluas RPP mencakup satu kompetensi dasar yang terdiri dari satu atau beberapa indikator untuk satu kali pertemuan atau lebih. RPP berfungsi sebagai acuan bagi guru untuk melaksanakan kegiatan pembelajaran agar lebih terarah dan efektif (Zendrato, 2016). Unsur-unsurnya meliputi standar kompetensi, kompetensi dasar, tujuan pembelajaran, bahan ajar, alokasi waktu, metode pembelajaran, serta karakteristik siswa. Unsur-unsur ini menjadi pertimbangan dalam penentuan metode pembelajaran.

Pembimbingan guru oleh kepala SMPN terkait RPP dilakukan dengan capaian skor $77,52 \%$. Dengan kata lain 22,49\% responden atau 15 orang guru tidak memperoleh 
bimbingan menyusun RPP. Hal ini mungkin terjadi jika guru tidak membuat RPP atau kepala sekolah selaku supervisor tidak menggunakan RPP ketika mensupervisi. Kondisi ini hendaknya tidak terus berlangsung mempertimbangkan peran sentral RPP sebagaimana dijelaskan sebelumnya. Uno (2009:3) menambahkan bahwa perencanaan pembelajaran penting untuk barometer mengukur keberhasilan atau "kegagalan" suatu pembelajaran. Dalam konteks supervisi, RPP akan menginformasikan standar kualitas pembelajaran kepada guru dan supervisor. Dengan demikian, RPP membantu memberikan standar kompetensi mengajar guru pada topik pelajaran tertentu sebagai dasar bagi supervisor melakukan penilaian. Hasil penilaian menjadi masukan pengembangan kompetensi guru yang dibutuhkan, yang ketika dilakukan akan berdampak pada peningkatan kualitas pembelajaran.

\subsection{Merencanakan kegiatan supervisi bersama guru}

Supervisi akademik perlu dilakukan secara sistematis agar dapat berjalan dengan baik dan mencapai tujuan yang ditetapkan (Larasati \& Sujanto, 2014). Konsekuensinya, supervisi akademik perlu perencanaan. Direktorat Jenderal Guru dan Tenaga Kependidikan (2019a: 18) menyebutkan ruang lingkup perencanaan supervisi akademik yaitu: (1) pengelolaan kurikulum, (2) persiapan pelaksanaan dan penilaian pembelajaran oleh guru, (3) pencapaian standar kompetensi kelulusan, standar proses, standar isi, dan peraturan pelaksanaannya, dan (4) peninjauan mutu pembelajaran. Perencanaan ini hendaknya memperhatikan prinsip obyektifitas, tanggung jawab, berkesinambungan, didasarkan pada Standar Nasional Pendidikan (SNP), serta didasarkan pada kebutuhan dan kondisi sekolah (Priansa, 2021).

Hasil penelitian menunjukkan bahwa sebagian besar guru yaitu $88,99 \%$ mengatakan bahwa kepala SMPN telah merencanakan supervisinya dan melibatkan guru dalam prosesnya. Ini berarti sebelum pelaksanaan supervisi, kepala sekolah mengkonfirmasi kesediaan guru untuk disupervisi dan melakukan penjadwalan supervisi bersama. Selanjutnya, kepala sekolah menelaah RPP, silabus, pengecekan prosedur bahan ajar, alat peraga atau media, serta alat penilaian yang akan digunakan guru dalam proses pembelajaran yang akan disupervisi (Burhanuddin, 2005). Jika diperlukan, kepala sekolah juga membantu guru merencanakan pembelajaran yang terdiri dari fase persiapan, pelaksanaan, dan evaluasi.

\subsection{Memonitor pelaksanaan pembelajaran yang dilakukan oleh guru}

Monitoring kegiatan pembelajaran dilaksanakan selama satu tahun ajaran berlangsung. Kegiatan ini penting untuk memastikan apakah pembelajaran sesuai dengan rencana dan mengarah pada pencapaian kompetensi yang telah ditargetkan sebagaimana dituangkan di 
dalam RPP. Menurut sebagian besar responden $(89,91 \%)$ kepala sekolah telah melaksanakan monitoring pembelajaran.

Monitoring merupakan serangkaian kegiatan yang ditujukan untuk memberikan informasi tentang sebab dan akibat dari suatu kebijakan yang terfokus pada kegiatan yang sedang dilaksanakan. Tujuannya yaitu mengetahui apakah kegiatan yang sedang berlangsung sesuai dengan perencanaan dan prosedur yang telah disepakati. Hasilnya berguna untuk proses kegiatan selanjutnya (BPPSDMK, 2017: 5).

\subsection{Melakukan evaluasi kegiatan pembelajaran yang dilakukan guru}

Hasil penelitian menurut sebagian besar guru $(92,66 \%)$ menunjukkan bahwa kepala sekolah telah melaksanakan evaluasi kegiatan pembelajaran. Sudijono (2006) menjelaskan bahwa evaluasi adalah (1) proses/kegiatan menentukan kemajuan pendidikan dengan cara membandingkan tingkat ketercapaian tujuan pendidikan dengan tujuan yang telah ditetapkan, (2) usaha memperoleh umpan balik. Umpan balik ini hendaknya benar-benar ditindaklanjuti untuk perbaikan pendidikan. Pelaksanaan evaluasi harus mengikuti prinsip-prinsip evaluasi agar dapat berjalan maksimal dan sesuai dengan tujuan evaluasi.

Kepala sekolah mengevaluasi kemampuan guru mengajar saat pembelajaran berlangsung. Evaluasi membandingkan keterampilan aktual mengajar guru dengan yang diharapkan sebagaimana tertuang dalam RPP serta tingkat ketercapaian tujuan pembelajaran. Kemampuan mengajar guru yang baik membutuhkan penguasaan materi yang diajarkan dan juga teknik mengajar yang disesuaikan dengan karakteristik siswa. Hal ini mensyaratkan penguasaan pengetahuan, teknologi, pedagogi, dan konten (Direktorat Jenderal Guru dan Tenaga Kependidikan, 2019b). Selanjutnya, hasil evaluasi kegiatan pembelajaran ini akan menjadi input bagi kepala sekolah untuk menentukan langkah pembinaan selanjutnya.

\subsection{Memotivasi guru untuk memanfaatkan teknologi informasi dalam pembelajaran di setiap mata pelajaran}

Pengembangan profesionalisme guru dalam konteks supervisi akademik tidak hanya memfokuskan pada peningkatan pengetahuan dan keterampilan mengajar guru, tetapi juga pada pembaharuan komitmen, kemauan, dan motivasi kerja (Direktorat Jenderal Guru dan Tenaga Kependidikan, 2019c). Motivasi dalam hal ini tidak hanya menyangkut persoalan etos kerja namun juga pemanfaatan teknologi informasi dalam pembelajaran.

Hasil penelitian menurut sebagian besar guru $(98,17 \%)$ menunjukkan bahwa kepala SMPN telah memberikan motivasi kepada guru untuk memanfaatkan Teknologi Informasi 
(TI). Pemanfaatan TI dalam pembelajaran menjadi tuntutan yang mendesak dewasa ini. Maraknya arus informasi dan beragam sumber informasi menjadikan guru bukan satu-satunya sumber belajar. Namun demikian, guru tetap memiliki peran yang strategis dalam pembelajaran. Oleh karena itu, penggunaan teknologi informasi dan komunikasi di sekolah hendaknya dimulai dari titik pangkal yang strategis pula yaitu guru (Miarso, 2004: 494).

\section{SIMPULAN}

Kepala SMPN di Klaten, Jawa Tengah telah melaksanakan supervisi akademik. Mereka memahami konsep, prinsip, teori/teknologi, karakteristik, dan kecenderungan perkembangan proses pembelajaran/bimbingan tiap mata pelajaran; membimbing guru menyusun silabus tiap mata pelajaran dalam kerangkakurikulum 2013; membimbing guru memilih dan menggunakan strategi/metode/teknik pembelajaran dengan melihat RPP; merencanakan kegiatan supervisi bersama guru, memonitor pelaksanaan pembelajaran; mengevaluasi pembelajaran dan memotivasi guru untuk memanfaatkan teknologi informasi. Dari ketujuh tugas tersebut, tugas memotivasi guru untuk memanfaatkan teknologi informasi dalam pembelajaran di setiap mata pelajaran merupakan tugas yang paling tinggi keterlaksanaannya. Sebaliknya, tugas yang paling rendah keterlaksanaannya adalah membimbing guru menyusun silabus tiap mata pelajaran sesuai dengan kurikulum yang berlaku.

Penelitian ini masih terbatas di tiga sekolah dalam satu kabupaten. Penelitian selanjutnya perlu diperluas dengan melebarkan jangkauan wilayah populasi. Selain itu, untuk memperoleh pemahaman yang lebih mendalam pada topik ini, penelitian hendaknya tidak hanya menggunakan pendekatan kuantitatif berupa survei namun juga menggunakan pendekatan kualitatif.

\section{DAFTAR PUSTAKA}

Arikunto, S. (2013). Prosedur penelitian: Suatu pendekatan praktik. Jakarta: Rineka Cipta BPPSDMK. (2017). Pedoman monitoring dan evaluasi pembelajaran. Jakarta: Pusat Pendidikan SdM Kesehatan Kementerian Kesehatan RI.

Burhanuddin, Y. (2005). Administrasi pendidikan. Bandung: Pustaka Setia.

Chanie, B.S. (2013). Conceptions about language syllabus and textbook based instructions: TEFL Graduate Students in Focus. Online Journal of Education Research, 2(4), 66-71. Retrieved from http://www.onlineresearchjournals.org/IJER

Direktorat Jenderal Guru dan Tenaga Kependidikan. (2019a). Supervisi dan penilaian kinerja guru (MPPKS-PKG). Jakarta: Kemdikbud.

Direktorat Jenderal Guru dan Tenaga Kependidikan.(2019b). Bahan ajar pengantar supervisi akademik. Jakarta: KemDikbud.

Direktorat Jenderal Guru dan Tenaga Kependidikan. (2019c). Pengelolaan pendidik dan tenaga kependidikan (MPPKS-PTK). Jakarta: Kemdikbud. 
Glickman, C.D., Gordon, S.P., \& Ross-Gordon, J.M. (2010). Supervision and instructional leadership: a developmental approach (11 $\mathrm{th}$ ed). Boston: Allyn and Bacon.

Kuncoro, H., Suntoro, I., \& Kandar, S. (2015). Peran kepala sekolah dalam implementasi kurikulum 2013 di sekolah menengah pertama kabupaten Tanggamus tahun pelajaran 2014/2015. Jurnal Manajemen Mutu Pendidikan. 3(1). Retrieved from http://jurnal.fkip.unila.ac.id/index.php/JMMP/issue/view/425

Larasati, A.M., \& Bejo, S. (2014). Pelaksanaan supervisi akademik oleh kepala sekolah di SMP Negeri 269 Jakarta (2013). Jurnal Improvement. 1(1). Retrieved from https://jurnalimprovement.wordpress.com/2014/03/01/pelaksanaan-supervisiakademik/

Makawimbang, J. H. (2011). Supervisi dan peningkatan mutu pendidikan. Bandung: Alfabeta. Novianti, H. (2015). Pelaksanaan supervisi akademik kepala sekolah dalam meningkatkan kinerja guru. Jurnal Manajer Pendidikan. 9(2), 350-358. Retrieved from https://ejournal.unib.ac.id/index.php/manajerpendidikan/article/view/1130/938

Okendu, J.N. (2012). The influence of instructional process and supervision on academic performance of secondary school students of Rivers State, Nigeria. Savap International, 2(3), Retrieved from http://www.savap.org.pk/

Permendiknas RI no 13 tahun 2007 tentang Standar Kompetensi Kepala Sekolah.

Prasojo, L. D. \& Sudiyono. (2002). Supervisi akademik. Yogyakarta: Gava Media.

Prasojo, L. D. \& Sudiyono. (2011). Supervisi pendidikan. Yogyakarta: Gava Media.

Priansa, D.J. \& Somad, R. (2021). Manajemen supervisi dan kepemimpinan kepala sekolah. Bandung: Alfabeta

Rahabav, P. (2016). The effectiveness of academic supervision for teachers. Journal of Education and Practice. 7(9), 47-55. Retrieved from https://files.eric.ed.gov/fulltext/EJ1095817.pdf

Republik Indonesia. (2007). Undang-Undang Republik Indonesia No. 14 Tahun 2005 tentang Guru dan Dosen. Tambahan Lembaran Negara RI Tahun 2007, No. 4723. Jakarta: Sekretariat Negara.

Rukajat, Ajat. (2018). Pendekatan penelitian kuantitatif. Yogyakarta. DeePublish

Sergiovanni, T. J., \& Starratt, R. J. (1987). Supervision: A re-definition (6th ed.). Boston: McGraw-Hill.

Sudijono, Anas. (2006). Pengantar evaluasi pendidikan. Jakarta: PT. Raja Grafindo Persada.

Sugiyono. (2014). Metode penelitian pendidikan, pendekatan kuantitatif, kualitatif, dan R\&D. Bandung: Alfabeta.

Susetya, Beny. (2017). Meningkatkan kemampuan guru dalam menyusun silabus dan RPP melalui supervisi akademik di SD N Gambiran Yogyakarta Tahun 2016. Jurnal Taman Cendekia. 1(2), 134-141. Retrieved from https://jurnal.ustjogja.ac.id/index.php/tamancendekia/article/view/1944/1126

Thaib, M. Amin dkk. (2005). Standar supervisi dan evaluasi pendidikan pada madrasah aliyah. Jakarta: Ditmapenda Tim.

Uno, Hamzah. (2009). Model pembelajaran. Menciptakan proses belajar mengajar yang kreatif. Jakarta: Bumi Aksara

Winarsunu, T. (2002). Statistik dalam penelitian psikologi dan pendidikan. Malang: UMM Press.

Yusufhadi, Miarso. (2004), Menyemai benih teknologi pendidikan. Jakarta: Kencana.

Zendrato, J. (2016). Tingkat penerapan rencana pelaksanaan pembelajaran di kelas: Suatu studi kasus di SMA Dian Harapan Jakarta. Jurnal Scholaria. 6(2), 58-73. https://doi.org/10.24246/j.scholaria.2016.v6.i2.p58-73 